\title{
Content and turnover rates of phosphorus in Daphnia pulex: Effect of food quality
}

\author{
John T. Lehman ${ }^{1} \&$ Trajče Naumoski ${ }^{2}$ \\ ${ }^{1}$ Division of Biological Sciences and Great Lakes Research Division, The University of Michigan, \\ Ann Arbor, MI 48109, U.S.A. \\ ${ }^{2}$ Hydrobiological Institute, Ohrid 97300, Yugoslavia
}

Keywords: zooplankton, Daphnia, phosphorus turnover, phosphorus content

\begin{abstract}
The content of phosphorus in individual Daphnia pulex and the rates at which the element turns over are functions of the $\mathrm{P}$ contents of algal cells fed to the zooplankton. Chlamydomonas and Ankistrodesmus were grown in semi-continuous cultures containing $2 \mu \mathrm{M}$ and $10 \mu \mathrm{M} \mathrm{PO}_{4}$ to produce differences in cellular $\mathrm{P}$ of the algae. Animals reared on the cultures high in $\mathrm{P}$ contained 60 percent more $\mathrm{P}$ than did animals of equal size that were fed low P cells. Daphnia with high body contents of $\mathrm{P}$ turned over that $\mathrm{P}$ faster than did the animals fed low $\mathrm{P}$ algae. Measured turnover rates imply that large differences exists between rates of gross $\mathrm{P}$ assimilation and $\mathrm{P}$ excretion for animals fed high and low $\mathrm{P}$ sources.
\end{abstract}

\section{Introduction}

Rates of release of $P$ from crustacean zooplankton have been the subject of many inquiries in recent years (see Harrison, 1980; Korstad, 1980; Lehman, 1980a for reviews). Rates are often equivalent to the loss each hour of at least several percent of the P-content of the animals (Lehman, 1980b). Much of the recycling owes to egestion and metabolism of recently ingested food and rapid declines in P-release occur when animals are separated from their diet (Scavia \& Gardner, 1982). Measured rates of P-release from well fed individuals may thus overestimate rates of which zooplankton catabolize or turn over their structural components. Release rates measured from starved plankton may likewise lead to erroneous conclusions because unfed animals may alter their physiology to accommodate their deprived state. Rates of nutrient turnover in the body mass of herbivorous zooplankton are important ecologically. They probably determine the speed and extent to which animals can change tissue stoichiometries in response to changes in quality and abundance of food. That, in turn, influences rates and proportions of nutrients available to higher trophic levels and thereby affects nutrient flux throughout the community.

Radiotracers have been used successfully to measure metabolism of $\mathrm{P}$ in Daphnia (Peters \& Rigler, 1973). The approach is simple and direct in concept and we adopted it for our work. We studied the effects of algal food type and algal $\mathrm{P}$ content on the content and turnover of $\mathrm{P}$ in Daphnia pulex. The investigation suggests that herbivorous zooplankton like Daphnia adjust very quickly to the nutrient quality of their food. Our animals renewed their body masses of $\mathrm{P}$ within a few hours under appropriate conditions.

\section{Methods}

Cultures of Daphnia pulex were maintained in screw-top glass vessels containing 41 of filtered epilimnetic water from Third Sister Lake, Michigan. Chlamydomonas reinhardtii and Ankistrodesmus falcatus were grown in semi-continuous cultures in MWC medium (Lehman, 1976) with the $\mathrm{PO}_{4}$ con-

Hydrobiologia 128, 119-125 (1985).

(c) Dr W. Junk Publishers, Dordrecht. Printed in the Netherlands. 
centration altered among treatments. For each species separate cultures were designated 'Low-P' (2 $\mu \mathrm{M} \mathrm{PO}$ ) and 'High-P' (10 $\left.\mu \mathrm{M} \mathrm{PO}_{4}\right)$. Each day one-half of the volume of each culture was removed and fresh sterile medium was added. Cells were harvested by centrifugation and were added to the Daphnia cultures. Optical densities of the Daphnia cultures ( $500 \mathrm{~nm}, 5 \mathrm{~cm}$ path) were monitored to assure that food did not become depleted. Calibration curves related cell abundances of each algal species to light absorbance. Abundances did not fall below $4 \times 10^{4}$ cells $\mathrm{ml}^{-1}$ in any treatment. All cultures were maintained at $20^{\circ} \mathrm{C}$ on a $16: 8$ light:dark cycle with illumination at c. $100 \mu$ Ein $\mathrm{m}^{-2} \mathrm{~s}^{-1}$ from cool-white fluorescent bulbs.

Relations between animal body size and P-content were determined for each treatment. Individual Daphnia were removed from their culture vessels and measured to the nearest $0.04 \mathrm{~mm}$ from head to base of tail spine. They were placed in $50 \mathrm{ml}$ distilled, deionized water and digested with potassium persulfate for $60 \mathrm{~min}$ (Menzel \& Corwin, 1965). The digests were neutralized and measured for SRP (Strickland \& Parsons, 1972).

Rates of P-turnover were determined by measuring the increase in specific activity of animals fed a radioactive diet. Algae were labelled with ${ }^{33} \mathrm{P}$ by incubating the food cultures with c. $50 \mu \mathrm{Ci}$ carrierfree $\mathrm{H}_{3}{ }^{33} \mathrm{PO}_{4}$ (New England Nuclear) for $24 \mathrm{~h}$. Labelled algae were harvested by centrifugation and were fed to Daphnia that had been preconditioned with identical but unlabelled food for 7 days. Individuals were then removed at intervals over the next 5 days, rinsed in non-radioactive medium, and measured for body length. They were transferred to $0.5 \mathrm{ml}$ Protosol (New England $\mathrm{Nu}$ clear) in scintillation vials, digested at $55^{\circ} \mathrm{C}$ overnight, and $10 \mathrm{ml}$ OCS (Amersham) was added. At the end of the experiment all samples were counted as a batch on a Beckman LS-210 liquid scintillation counter with the detection window optimized manually for ${ }^{33} \mathrm{P}$.

\section{Results}

The nutrient content of algal food had a marked effect on P-content of Daphnia pulex (Fig. 1). For both Chlamydomonas and Ankistrodesmus, animals fed from high-P treatments contained more $\mathbf{P}$ than did animals fed low-P algae (analysis of covariance). P-content of the animals varied approximately with the cube of body length in all treatments except low-P Chlamydomonas where the power of the relation was less than $3(P<0.05)$. The main effect of food quality, however, did not involve the slope of P-content vs length; rather it concerned the elemental content of Daphnia body tissue. Adjusted to equivalent body length, high-P food resulted in higher $\mathbf{P}$ content in Daphnia $(\mathrm{P}<0.0001)$ by a factor of 1.65 for Chlamydomonas and 1.59 for Ankistrodesmus. The main effect is unquestionably the $\mathrm{P}$ content of the algae because there are no differences between the effects of food species (Chlamydomonas vs Ankistrodesmus) at either high or low levels $(P>0.5)$. In our semi-continuous cultures at harvest the low-P Chlamydomonas contained $3.4 \times 10^{-9} \mu \mathrm{mol} \quad \mathrm{P}$ cell $^{-1}$ and high-P Chlamydomonas contained $7.8 \times 10^{-9} \mu \mathrm{mol} P$ cell $^{-1}$; low-P and high-P Ankistrodesmus contained $3.3 \times 10^{-9}$ and $8.9 \times 10^{-9} \mu \mathrm{mol} \mathrm{P}$ cell ${ }^{-1}$, respectively.

Time courses of isotope equilibrium are shown in Fig. 2. Specific activities for individual Daphnia were calculated from $\mathrm{cpm}$ animal ${ }^{-1}$ (measured directly) and the body mass of $\mathrm{P}$ ( $\mathrm{nmol} \mathrm{P}$ animal ${ }^{-1}$ ) estimated from the regressions plotted in Fig. 1. Analyses were confined to animals greater than $1 \mathrm{~mm}$ length, because smaller animals were poorly represented in Fig. 1. Moreover, the smaller sizes include animals newborn in the labelled food and we were interested only in rates of isotope exchange in animals that originally contained large unlabelled pools of $\mathrm{P}$. Curves were fit to the data by non-linear regression using the model:

$A=A_{\max }\left(1-e^{-k t}\right)$

where $\mathbf{A}$ is specific activity, $\mathbf{A}_{\max }$ is the asymptotic maximum, $t$ is time and $k$ is a rate constant $\left(\right.$ time $\left.^{-1}\right)$. Activities are reported as cpm because all samples were counted with identical efficiency (c. $90 \%$ ) and the results are comparable.

Turnover times for $\mathrm{P}$ in the body tissue of Daphnia pulex are listed in Table 1. Animals fed algae low in $\mathrm{P}$-content turned over their body-P in 2 days or less. When fed algae high in $\mathrm{P}$, however, the animals exchanged their body-P in a matter of several hours. 
LOW-P CHLAMYDOMONAS

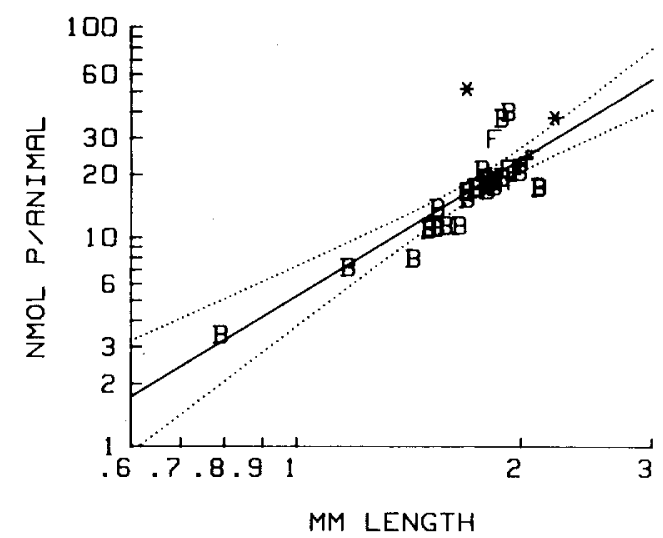

HIGH-P CHLAMYDOMONAS

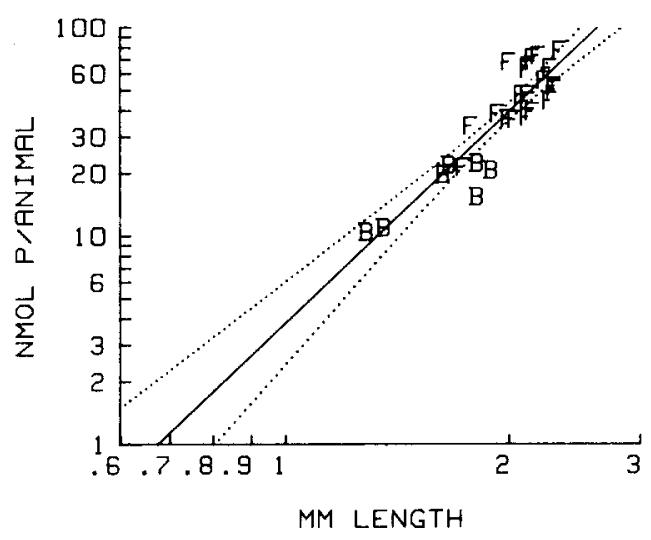

LOW-P RNKISTRODESMUS

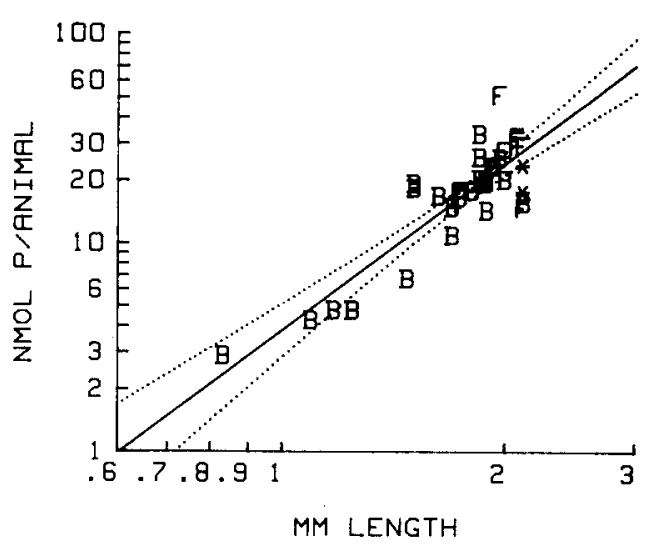

HIGH-P RNKISTRODESMUS

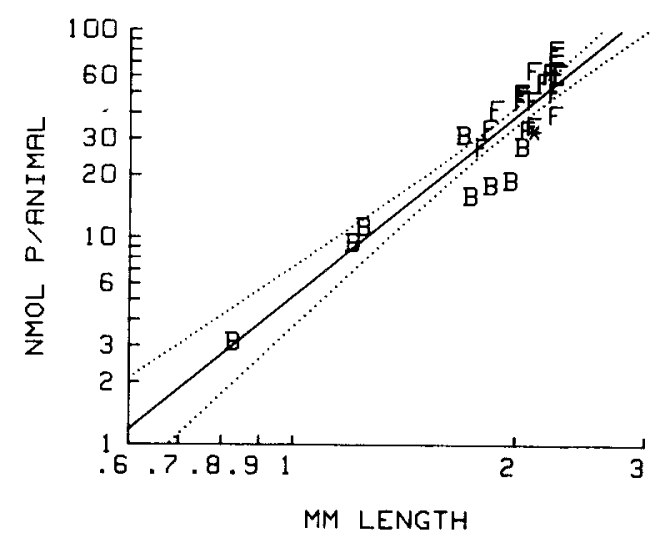

Fig. 1. Log-log relationships between body size and P content of individual Daphnia pulex fed high-P and low-P cultures of Chlamydomonas (left) and Ankistrodesmus (right). Symbols indicate whether the individuals were without eggs (B), egg-bearing (F), or ephippial $\left.{ }^{*}\right)$. Linear regressions are fit to each data set, and $95 \%$ confidence intervals of the regressions are shown.

Table 1. Turnover times of $\mathrm{P}$ in Daphnia pulex computed as $1 / \mathrm{k}$ by fitting equation (1) to the data in Fig. 2 .

\begin{tabular}{lc}
\hline & Turnover time (h) \\
\hline Low-P Chlamydomonas & 47.6 \\
Low-P Ankistrodesmus & 36.0 \\
High-P Chlamydomonas & 6.7 \\
High-P Ankistrodesmus & 4.7 \\
\hline
\end{tabular}

\section{Discussion}

The rates at which Daphnia turn over the $\mathrm{P}$ bound in their body tissue evidently depend greatly on the amount of $\mathbf{P}$ available to them in their diet.
Animals husband the nutrient most efficiently when it is less available in their food. Overall tissue contents of $\mathrm{P}$ are lower among Daphnia fed a diet poor in $P$. The animals thus contain less $P$ and they retain it more efficiently when it is less abundant.

The results seem reasonable from both ecological and physiological points of view. The implications they hold for models of nutrient dynamics in aquatic ecosystems have not been considered previously, however. Even in models which include variable nutrient contents for the algae, zooplankton are treated as though they possess constant, fixed stoichiometry. Our results show not only that this is unlikely, but that the animals turn over their constitutive $\mathrm{P}$ so fast in some cases that they may re- 
LOW-P CHLAMYDOMONAS
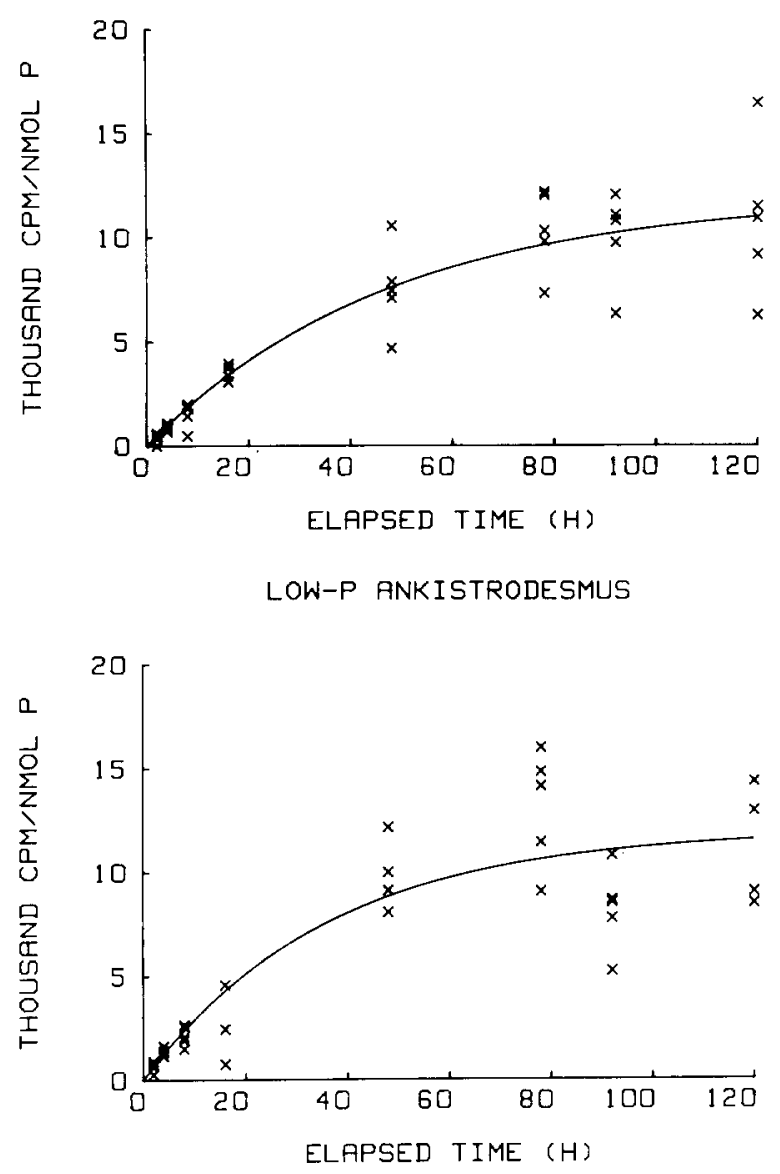

HIGH-P CHLRMYDOMONRS
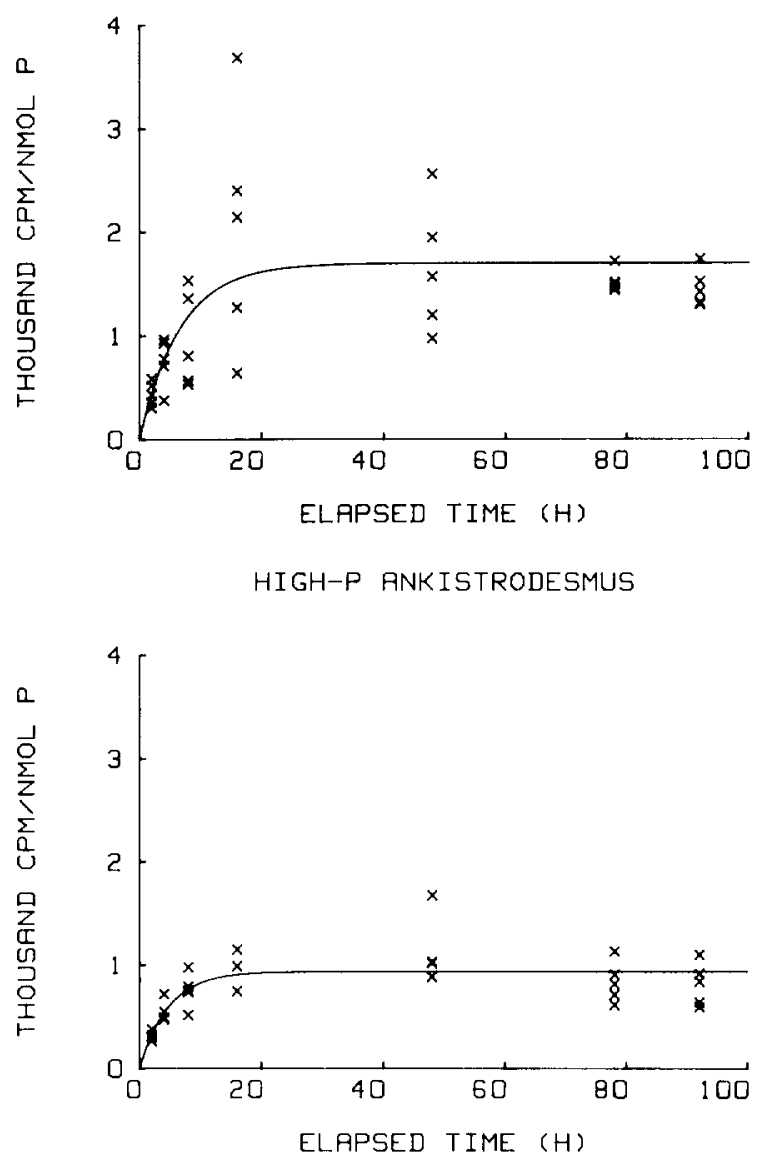

Fig. 2. Radiophosphorus content of the total mass of $\mathrm{P}$ in individual Daphnia pulex after the addition of labelled food. Curves were fit by non-linear regression using equation (1). Turnover times inferred from the plots are listed in Table 1.

spond rapidly to changes in food quality. Daphnia body tissue does not mimic the composition of ingested food, but it is constrained and influenced by it.

We did not purge or dissect gut contents from the Daphnia prior to our analyses, but differences among algal cells contained in those guts do not affect our interpretations. Based on Geller's (1975) data for Scenedesmus, Daphnia pulex $2 \mathrm{~mm}$ in length can pack c. $2 \times 10^{6} \mu \mathrm{m}^{3}$ of that green alga into their guts. We estimated the maximum differences between animals that could be ascribed to differences in the P-content of food held in the gut from the sizes and cellular P contents of our algae. These differences were less than $0.1 \mathrm{nmol} P$ ani$\mathrm{mal}^{-1}$ whereas measured differences in $\mathrm{P}$ content between $2 \mathrm{~mm}$ Daphnia fed low-P and high-P algae were greater than $15 \mathrm{nmol}$ animal $^{-1}$. The gut contents contributed to less than one percent of the measured differences.

The turnover times in Table 1 are qualitatively consistent with the findings of Lehman (1980b) that Daphnia fed with P-deficient Chlamydomonas released $\mathrm{P}$ equivalent to $1.24 \% \mathrm{~h}^{-1}$ of their body mass of $\mathrm{P}$ whereas animals fed nutrient-sufficient cells released $1.95 \% \mathrm{~h}^{-1}$. Our turnover times are much faster than these excretion rates imply, however, and they even exceed rates that might be expected from smaller metazoa or protozoa based on body equivalent excretion rates (Taylor \& Lean, 1981).

The reason for this discrepancy is that the isotop- 
ic equilibria we measured integrate more of the animals' physiology than do excretion rates alone. Conover \& Francis (1973) described a 4 compartment model that is appropriate to our experimental conditions. In addition to dissolved $\mathrm{P}\left(\mathrm{P}_{\mathrm{D}}\right)$ and $\mathrm{P}$ in algae $\left(\mathrm{P}_{\mathrm{Q}}\right)$, the total body $\mathrm{P}$ of Daphnia $\left(\mathrm{P}_{\mathrm{Z}}\right)$ is presumed to consist of 2 compartments, $P_{1}$ and $P_{2}$. $P_{1}$ is a metabolically active exchangeable pool and $\mathrm{P}_{2}$ is a larger, structural component. This description of Daphnia conforms to empirical work by Peters \& Rigler (1973), and it parallels the patterns of $\mathrm{C}$ metabolism in these animals (Lampert \& Gabriel, 1984). The equations which describe changes in specific activities of all these pools can be derived by the approach of Lampert \& Gabriel (1984). For pool $P_{1}$ :

$$
\begin{aligned}
& \mathrm{dP}_{1} / \mathrm{dt}=\left(\rho_{\mathrm{Q} 1}-\rho_{1 \mathrm{D}}-\rho_{12}\right) \mathrm{P}_{1}+\rho^{2} \mathrm{P}_{2} \\
& \mathrm{dP}_{1}^{*} / \mathrm{dt}=\left(\rho_{\mathrm{Q} 1} \mathrm{a}_{\mathrm{Q}}-\rho_{1 D} \mathrm{a}_{1}-\rho_{12} \mathrm{a}_{1}\right) \mathrm{P}_{1}+\rho_{21} \mathrm{a}_{2} \mathrm{P}_{2}
\end{aligned}
$$

where $\rho_{\mathrm{Q} 1}$ is the rate of gross assimilation of $\mathrm{P}$ by Daphnia, $\rho_{1 \mathrm{D}}$ is excretion rate, and $\rho_{12}$ and $\rho_{21}$ are the exchange rates between pools 1 and $2,(\%$ total Daphnia body $\left.\mathrm{P}^{-1}\right), \mathrm{P}_{1}^{*}$ is radiophosphorus content (dpm) and $a_{Q}, a_{1}, a_{2}$ are the specific activities of alga and animal $\mathrm{P}$ pools (dpm nmol- $\mathrm{P}^{-1}$ ). Similarly,

$\mathrm{dP}_{2} / \mathrm{dt}=\rho_{12} \mathrm{P}_{1}-\rho_{21} \mathrm{P}_{2}$

$\mathrm{dP} \mathrm{P}_{2}^{*} / \mathrm{dt}=\rho_{12} \mathrm{a}_{1} \mathrm{P}_{1}-\rho_{21} \mathrm{a}_{2} \mathrm{P}_{2}$

The specific activity of the algae in our experiments can change during an incubation because the radioactive cells are present together with animals that are initially unlabelled. Excreted $P$ can be incorporated into the algae:

$$
\begin{aligned}
& \mathrm{dQ} / \mathrm{dt}=\rho_{\mathrm{DQ}} \mathrm{Q}-\rho_{\mathrm{Q} 1} \mathrm{P}_{1} \\
& \mathrm{dQ} * / \mathrm{dt}=\rho_{\mathrm{DQ}} \mathrm{a}_{\mathrm{D}} \mathrm{Q}-\rho_{\mathrm{Q} 1} \mathrm{a}_{\mathrm{Q}} \mathrm{P}_{1}
\end{aligned}
$$

where $\rho_{\mathrm{DQ}}$ is the rate of uptake of $\mathrm{P}(\%$ algal cell $\left.\mathbf{P ~ h}^{-1}\right)$; and $\mathrm{a}_{\mathbf{D}}$ is the specific activity of $\mathbf{P}$ incorporated by the algae (dpm nmol-P ${ }^{-1}$ ). Under experiment conditions concentrations of $\mathrm{PO}_{4}$ were sufficiently available that we feel justified claiming that $\rho_{\mathrm{DQ}}$ is a constant, independent of phosphate levels. The differential equations describing the changes in specific activity of individual pools are:

$$
\begin{aligned}
& \frac{\mathrm{da}_{\mathrm{Q}}}{\mathrm{dt}}=\frac{\mathrm{d}\left(\mathrm{Q}^{*} / \mathrm{Q}\right)}{\mathrm{dt}}=\frac{1}{\mathrm{Q}} \frac{\mathrm{dQ}}{\mathrm{dt}}-\frac{\mathrm{a}_{\mathrm{Q}}}{\mathrm{Q}} \frac{\mathrm{dQ}}{\mathrm{dt}}=\rho_{\mathrm{SQ}}\left(\mathrm{a}_{\mathrm{D}}-\mathrm{a}_{\mathrm{Q}}\right) \\
& \mathrm{da}_{1} / \mathrm{dt}=\frac{\rho_{\mathrm{Q} 1}}{\mathrm{~S}_{1}}\left(\mathrm{a}_{\mathrm{Q}}-\mathrm{a}_{1}\right)+\frac{\rho_{21}}{\mathrm{~S}_{1}}\left(\mathrm{a}_{2}-\mathrm{a}_{1}\right) \\
& \mathrm{da}_{2} / \mathrm{dt}=\frac{\rho_{12}}{\mathrm{~S}_{2}}\left(\mathrm{a}_{1}-\mathrm{a}_{2}\right)
\end{aligned}
$$

where $S_{1}$ and $S_{2}$ are the fractions of total Daphnia $P$ in pools 1 and 2 respectively. Because the experiment situation is such that algae obtain nutrients released by the Daphnia we will assume $\mathrm{a}_{\mathrm{D}}=\mathrm{a}_{1}$. To solve this system we use the additional information that the fractions $S_{1}$ and $S_{2}$ remain constant, so

$$
a_{Z}=a_{1} S_{1}+a_{2} S_{2}
$$

This constraint forces a dependency among coefficients $\rho_{\mathrm{Q} 1}, \rho_{1 \mathrm{D}}, \rho_{21}, \rho_{12}$, and $\mathrm{S}_{2}$ as described by Lampert \& Gabriel (1984; their equation 4).

The equations ( 8 ) to (10) describe a linear homogeneous system with constant coefficients, which has an interdependent family of solutions. For the specific activity of whole Daphnia $\left(\mathrm{a}_{\mathrm{Z}}\right)$, which we measured, the general solution is:

$a_{Z}(t)=A_{\max }\left(1-e^{\lambda t}\right)$

where $\lambda$ is a (negative) eigenvalue obtained by solving the quadratic equation:

$\lambda^{2}+b \lambda+c=0$

with

$\mathrm{b}=\rho_{\mathrm{DQ}}+\frac{\rho_{\mathrm{Q} 1}}{\mathrm{~S}_{1}}+\frac{\rho_{21}}{\mathrm{~S}_{1}}+\frac{\rho_{12}}{\mathrm{~S}_{2}}$

$\mathrm{c}=\frac{\rho_{\mathrm{DQ}} \rho_{21}}{\mathrm{~S}_{1}}+\frac{\rho_{\mathrm{DQ}} \rho_{12}}{\mathrm{~S}_{2}}+\frac{\rho_{\mathrm{Q} 1} \rho_{12}}{\mathrm{~S}_{1} \mathrm{~S}_{2}}$.

Equation (12) is effectively identical to equation (1), fit to our data. We find that the rate of approach to isotope equilibrium depends on rates of gross assimilation, internal transfers among pools, and 
on rates of uptake by the algae, which in turn are dependent on nutrient regeneration. For characteristic values of the parameters (e.g., Table 1: Lampert \& Gabriel, 1984), $\lambda$ is most sensitive to values of $\rho_{12}$, followed by $\rho_{\mathrm{Q} 1}$ and $\rho_{\mathrm{DQ}}$; the other independent coefficients are of lesser significance.

Other authors have made simplifying assumptions about experimental conditions in order to decipher the behavior of radiotracers introduced in an alga-herbivore system (e.g., Conover \& Francis, 1973; Lampert \& Gabriel, 1984), with much success. Nonetheless, it is especially important to consider the overall behavior of equations (8) to (10) when interpreting the changes in turnover rate we report in Table 1. Lampert (1977), for instance, reports rates of gross assimilation of $\mathrm{C}$ at $60 \% \mathrm{~d}^{-1}\left(=0.025 \mathrm{~h}^{-1}\right)$ for animals c. $2 \mathrm{~mm}$ in length. Gross assimilation reported by Peters (1975), for $P$, was equivalent to $0.025 \mathrm{~h}^{-1}$. We measured rate constants for high-P cells of 0.15 and $0.21 \mathrm{~h}^{-1}$, which exceed gross assimilation. The reason for this is that when Daphnia are fed food high in $\mathrm{P}$ content, the transfer rate between internal pools $\left(\rho_{12}\right)$ becomes elevated. In the most extreme limit of this phenomenon, Daphnia might be regarded as a single pool of $P$, so that $a_{Z}$ is substituted for $a_{1}$ in equations (8) to (10) and $a_{1}=a_{2}$. Then

$\mathrm{a}_{\mathrm{Z}}(\mathrm{t})=\frac{\rho_{\mathrm{Q} 1} \mathrm{a}_{\mathrm{Q}}\left(\mathrm{t}_{\mathrm{o}}\right)}{\rho_{\mathrm{Q} 1}+\rho_{\mathrm{DQ}}}\left[1-\mathrm{e}^{-\left(\rho_{\mathrm{Q} 1}+\rho_{\mathrm{DQ}}\right) \mathrm{t}}\right]$

and isotope dynamics depend both on the rates of gross assimilation of $\mathrm{P}$ by Daphnia and on the rates at which excreted $P$ is incorporated by the algae.

Based on the preceeding line of reasoning we conclude that the body tissues of Daphnia can equilibrate to new food regimes faster than one would conclude from excretion measurements or gross assimilation. The differences we measured between Daphnia as a function of food quality consequently reflect differences in assimilation of $P$ from the algal food and internal exchange dynamics. Peters \& Rigler (1973) reported that Daphnia species fed Rhodotorula contained constant amounts of $\mathbf{P}$ per unit mass regardless of temperature, food availability or body size. The phosphorus content of the food was variable in their experiments; the reported standard deviation of $\mathbf{P}$ cell ${ }^{-1}$ was almost $50 \%$ of the mean value. Combining their discoveries with our own, we conclude that the amount of $P$ per unit mass in their diet is a major determinant of P-content and turnover rates in the tissue of these herbivores.

\section{Acknowledgements}

We thank P. Rago for providing the calibration data for computing abundances of algal cells from optical densities. This work was supported by NSF Grant DEB81-16428.

\section{References}

Conover, R. J. \& V. Francis, 1973. The use of radioactive isotopes to measure the transfer of materials in aquatic food chains. Mar. Biol. 18: 272-283.

Geller, W., 1975. Die Nahrungsaufnahme von Daphnia pulex in Abhängigkeit von der Futterkonzentration, der Temperatur, der Körpergröße und dem Hungerzustand der Tiere. Arch. Hydrobiol., Suppl. 48: 47-107.

Harrison, W. G., 1980. Nutrient regeneration and primary production in the sea. In P. G. Falkowski (ed.), Primary productivity in the sea. Plenum Press, N.Y.: $433-460$.

Korstad, J. E., 1980. Laboratory and field studies of phytoplankton - zooplankton interactions. Ph.D. Thesis, Univ. Michigan, 212 pp.

Lampert, W., 1977. Studies on the carbon balance of Daphnia pulex de Geer as related to environmental conditions, 2 . The dependence of carbon assimilation on animal size, temperature, food concentration and diet species. Arch. Hydrobiol., Suppl. 48: 310-335.

Lampert, W. \& W. Gabriel, 1984. Tracer kinetics in Daphnia: an improved two-compartment model and experimental test. Arch. Hydrobiol. 100: 1-20.

Lehman, J. T., 1976. Photosynthetic capacity and luxury uptake of carbon during phosphate limitation in Pediastrum duplex (Chlorophyceae). J. Phycol. 12: 190-193.

Lehman, J. T., 1980a. Nutrient recycling as an interface between algae and grazers in freshwater communities. Am. Soc. Limnol. Oceanogr., Spec. Symp. 3: 251-263.

Lehman, J. T., 1980b. Release and cycling of nutrients between planktonic algae and herbivores. Limnol. Oceanogr. 25: $620-632$

Menzel, D. \& N. Corwin, 1965. The measurement of total phosphorus in seawater based on the liberation of organically bound fractions by persulfate oxidation. Limnol. Oceanogr. 10: $280-282$.

Peters, R. H., 1975. Phosphorus excretion and the measurement of feeding and assimilation by zooplankton. Limnol. Oceanogr. 20: 858-859.

Peters, R. H. \& F. H. Rigler, 1973. Phosphorus release by Daphnia. Limnol. Oceanogr. 18: 821-839.

Scavia, D. \& W. S. Gardner, 1982. Kinetics of nitrogen and 
phosphorus release by Daphnia magna. Hydrobiologia 96 : 105-111.

Strickland, J. D. \& T. R. Parsons, 1972. A practical handbook of seawater analysis, 2nd Edn. Bull. Fish. Res. Bd Can., $167 \mathrm{pp}$.

Taylor, W. D. \& D. R. S. Lean, 1981. Radiotracer experiments on phosphorus uptake and release by limnetic microzooplankton. Can. J. Fish. aquat. Sci. 38: 1316-1321.

Received 7 March 1984; in revised form 19 March 1985; accepted 20 April 1985. 